\title{
Tissue Doppler Imaging-Derived Myocardial Acceleration During Isovolumetric Contraction Predicts Pulmonary Capillary Wedge Pressure in Patients With Reduced Ejection Fraction
}

\author{
Alaa Mabrouk Salem Omar, PhD; Hidekazu Tanaka, MD, PhD; Kensuke Matsumoto, MD; \\ Kazuhiro Tatsumi, MD, PhD; Tatsuya Miyoshi, MD; Mana Hiraishi, MD; \\ Takayuki Tsuji, MD; Akihiro Kaneko, MD; Keiko Ryo, MD; Yuko Fukuda, MD; \\ Hiroya Kawai, MD, PhD; Ken-ichi Hirata, MD, PhD
}

\begin{abstract}
Background: Tissue Doppler imaging-obtained isovolumetric myocardial acceleration (IVA) is load independent, reportedly predicts systolic functions, and correlates with exercise capacity in patients with reduced ejection fraction (EF). We hypothesized that IVA correlates with the pulmonary capillary wedge pressure (PCWP) in patients with reduced $\mathrm{EF}$.

Methods and Results: Of 113 patients, correlations between PCWP and IVA were done for all patients, 48 patients with $\mathrm{EF} \geq 55 \%$, and 65 patients with $\mathrm{EF}<55 \%$. Results were compared to the correlation between PCWP and other echocardiographic predictors. IVA correlated moderately with PCWP in all patients $(r=0.54, P<0.0001)$ and was comparable to the $\mathrm{E} / \mathrm{A}$ and $\mathrm{E} / \mathrm{e}^{\prime}$ ratios. In patients with $\mathrm{EF} \geq 55 \%$, IVA lost correlation and the only predictor was the E/e' ratio $(r=0.08,0.58, P=0.58,<0.0001)$. In patients with $E F<55 \%$, IVA was better than $E / A$ and $E / e^{\prime}(r=0.72,0.61$, $0.51, P<0.0001)$, especially for atrial fibrillation or when $E / e^{\prime}$ fell between 8 and 15 . Furthermore, IVA $>1.60 \mathrm{~m} / \mathrm{s}^{2} \mathrm{can}$ predict PCWP $\geq 15 \mathrm{mmHg}$, with a sensitivity of $95 \%$, specificity of $73 \%$, and an area under the curve of 0.867 $(P<0.0001)$.
\end{abstract}

Conclusions: IVA can predict PCWP in patients with reduced EF, and can be considered an alternative to the E/e' ratio for patients with atrial fibrillation or E/e' ratio between 8 and 15 . (Circ $J$ 2012; 76: 1399-1408)

Key Words: Echocardiography; Heart failure; Left ventricular function; Tissue Doppler imaging

$\mathbf{H}$ eart failure (HF) is a complex clinical condition caused by systolic or diastolic dysfunction and in either case it leads to elevation of the pulmonary capillary wedge pressure (PCWP). ${ }^{1-3}$ Invasive cardiac catheterization remains the gold standard for PCWP assessment. ${ }^{4,5}$ In clinical practice, however, PCWP can be non-invasively assessed by echocardiography using mostly diastolic parameters. Systolic variables, such as the ejection fraction (EF), do not correlate with PCWP because they are derived from the load-dependent ejection systolic phase. The isovolumetric phase, on the other hand, appears to be load independent, and therefore variables derived from this phase, such as the tissue Doppler imaging (TDI)-derived mitral annular isovolumetric velocity (IVV) and acceleration (IVA), have been suggested for assessing LV systolic function. Despite showing biphasic motion patterns in normal subjects, which may be altered if contractility is impaired, positive wave IVV and IVA have been validated as load-independent variables useful for the assessment of myocardial contractility of both the left and right ventricles in animals as well as in humans. ${ }^{6-11}$ Moreover, IVV was reported to correlate with right ventricular (RV) filling pressure, ${ }^{12}$ and both IVV and IVA have been reported to predict exercise capacity in patients with reduced EF. ${ }^{13}$ Ventricular torsion during ejection and its subsequent early diastolic untwist, are reported as interdependently affecting diastolic filling. Myocardial untwist also occurs during isovolumetric contraction (IC), the velocity of which reportedly seems to affect the force of cardiac contraction during ejection, and the timing of systolic cross-over into diastole in patients with reduced left ventricular (LV) EF. ${ }^{13}$ Therefore, it seems that understanding IC is essential to explain this systolic-diastolic interaction and its effect on diastolic filling.

Received December 16, 2011; revised manuscript received January 24, 2012; accepted February 1, 2012; released online April 3, 2012

Time for primary review: 20 days

Division of Cardiovascular Medicine, Department of Internal Medicine, Kobe University Graduate School of Medicine, Kobe, Japan

Mailing address: Hidekazu Tanaka, MD, PhD, Division of Cardiovascular Medicine, Department of Internal Medicine, Kobe University

Graduate School of Medicine, 7-5-1 Kusunoki-cho, Chuo-ku, Kobe 650-0017, Japan. E-mail: tanakah@med.kobe-u.ac.jp

ISSN-1346-9843 doi:10.1253/circj.CJ-11-1463

All rights are reserved to the Japanese Circulation Society. For permissions, please e-mail: cj@j-circ.or.jp 


\begin{tabular}{|c|c|c|c|}
\hline & All $(n=113)$ & $E F \geq 55 \%(n=48)$ & $E F<55 \%(n=65)$ \\
\hline Age (years) & $62 \pm 14$ & $63 \pm 15$ & $61 \pm 12$ \\
\hline $\operatorname{Sex}(M / F)$ & $63 / 50$ & $18 / 30$ & $45 / 20$ \\
\hline Rhythm (sinus/AF) & $92 / 21$ & $43 / 5$ & $49 / 16$ \\
\hline Mean BP $(\mathrm{mmHg})$ & $89 \pm 19$ & $89 \pm 20$ & $89 \pm 19$ \\
\hline LV end-systolic volume (ml) & $128 \pm 66$ & $158 \pm 69$ & $89 \pm 36^{*}$ \\
\hline EF (\%) & $49 \pm 17$ & $66 \pm 6$ & $36 \pm 12^{*}$ \\
\hline Left atrial volume (ml) & $66 \pm 32$ & $63 \pm 26$ & $70 \pm 36$ \\
\hline \multicolumn{4}{|l|}{ NYHA, n (\%) } \\
\hline I/II/III/VI & 29/49/26/9 & $13 / 21 / 9 / 2$ & $16 / 28 / 17 / 6$ \\
\hline \multicolumn{4}{|l|}{ Medication, n (\%) } \\
\hline ARB/ACEI & $49(43 \%)$ & $21(44 \%)$ & $28(43 \%)$ \\
\hline$\beta$-blockers & $37(33 \%)$ & $15(31 \%)$ & $22(34 \%)$ \\
\hline Calcium-channel blockers & $34(30 \%)$ & $14(29 \%)$ & $20(31 \%)$ \\
\hline Diuretics & $66(58 \%)$ & $22(46 \%)$ & $44(67 \%)$ \\
\hline Digoxin & $39(35 \%)$ & $9(19 \%)$ & $30(46 \%)$ \\
\hline \multicolumn{4}{|l|}{ Etiology } \\
\hline Dilated cardiomyopathy & $38(34 \%)$ & $7(15 \%)$ & $31(48 \%)$ \\
\hline Aortic valve disease & $24(21 \%)$ & $10(21 \%)$ & $14(22 \%)$ \\
\hline Pulmonary hypertension & $14(12 \%)$ & $10(21 \%)$ & $4(6 \%)$ \\
\hline Ischemic cardiomyopathy & $11(10 \%)$ & $3(6 \%)$ & $8(12 \%)$ \\
\hline Hypertrophic cardiomyopathy & $8(7 \%)$ & $5(10 \%)$ & $3(5 \%)$ \\
\hline Hypertension & $5(4 \%)$ & $4(8 \%)$ & $1(1 \%)$ \\
\hline Atrial septal defect & $5(4 \%)$ & $4(8 \%)$ & $1(1 \%)$ \\
\hline Systemic lupus erythematosus & $1(1 \%)$ & $1(2 \%)$ & $0(0 \%)$ \\
\hline Peripartum cardiomyopathy & $1(1 \%)$ & $0(0 \%)$ & $1(1 \%)$ \\
\hline Other & $6(5 \%)$ & $4(8 \%)$ & $2(3 \%)$ \\
\hline
\end{tabular}

Accordingly, the objective of this study was to test the hypothesis that the TDI-derived IVA of the septal mitral annulus can predict the PCWP in patients with reduced EF.

\section{Methods}

\section{Study Population}

Between January 2008 and April 2011, we retrospectively studied 155 patients admitted to hospital for the management of HF of different causes. All patients underwent echocardiographic examination and right-heart cardiac catheterization; 42 patients $(27 \%)$ were excluded from all subsequent analyses because of poor echocardiographic images (4 patients), more than mild mitral stenosis (8 patients), severe mitral regurgitation (10 patients), negative or unclear IC velocity waves (12 patients), and an interval of more than 1 week between echocardiographic and catheterization studies (3 patients); 2 patients with constrictive pericarditis and 3 patients with cardiac sarcoidosis were also excluded because of known problems in calculating PCWP using the conventional echocardiographic variables. ${ }^{14}$ Accordingly, the patient study group consisted of 113 patients. Table 1 summarizes their basic clinical data, and etiologies and therapies for HF. The mean age was $62 \pm 14$ years (range, 23-87 years), 50 patients $(44 \%)$ were female, and the mean EF was $49 \pm 17 \%$; $92(81 \%)$ were in sinus rhythm and $21(19 \%)$ had atrial fibrillation (AF). The study was approved by the institution's local ethics committee, and written informed consent was given by all patients.

\section{Echocardiographic Examination}

All echocardiographic studies were performed with a commercially available echocardiography systems equipped with a 2.5-MHz multifrequency phased array transducer (Vivid 7, GE-Vingmed, Horton, Norway or Aplio Artida, Toshiba Medical Systems, Tochigi, Japan). Digital routine grayscale 2-dimensional and tissue Doppler cine loops from 3 consecutive beats were obtained at end-expiratory apnea from standard apical views at depths of $12-20 \mathrm{~cm}$. Sector width was optimized to allow for complete myocardial visualization while maximizing the frame rate. Gain settings were adjusted for routine clinical grayscale 2D imaging to optimize endocardial definitions. LVEF was calculated from the apical 2- and 4-chamber images using the biplane Simpson's technique. ${ }^{15}$ Left atrial volume was calculated using the prolate ellipse method..$^{15}$ All measurements were made in $\geq 3$ consecutive cardiac cycles and in $\geq 5$ cycles if the patient's rhythm was AF and average values were used for the final analyses. To confirm reproducibility, 60 randomly selected measurements were redone by the same investigator but in a separate setting and by a different investigator who was blinded to all previous data.

\section{Pulsed-Wave Doppler Examination}

The pulsed-wave Doppler-derived transmitral velocity and digital color tissue Doppler-derived mitral annular velocity were obtained from the apical 4-chamber view. The early diastolic wave velocity (E), late diastolic atrial contraction wave velocity (A), and the E-wave deceleration time (E-DcT) were 


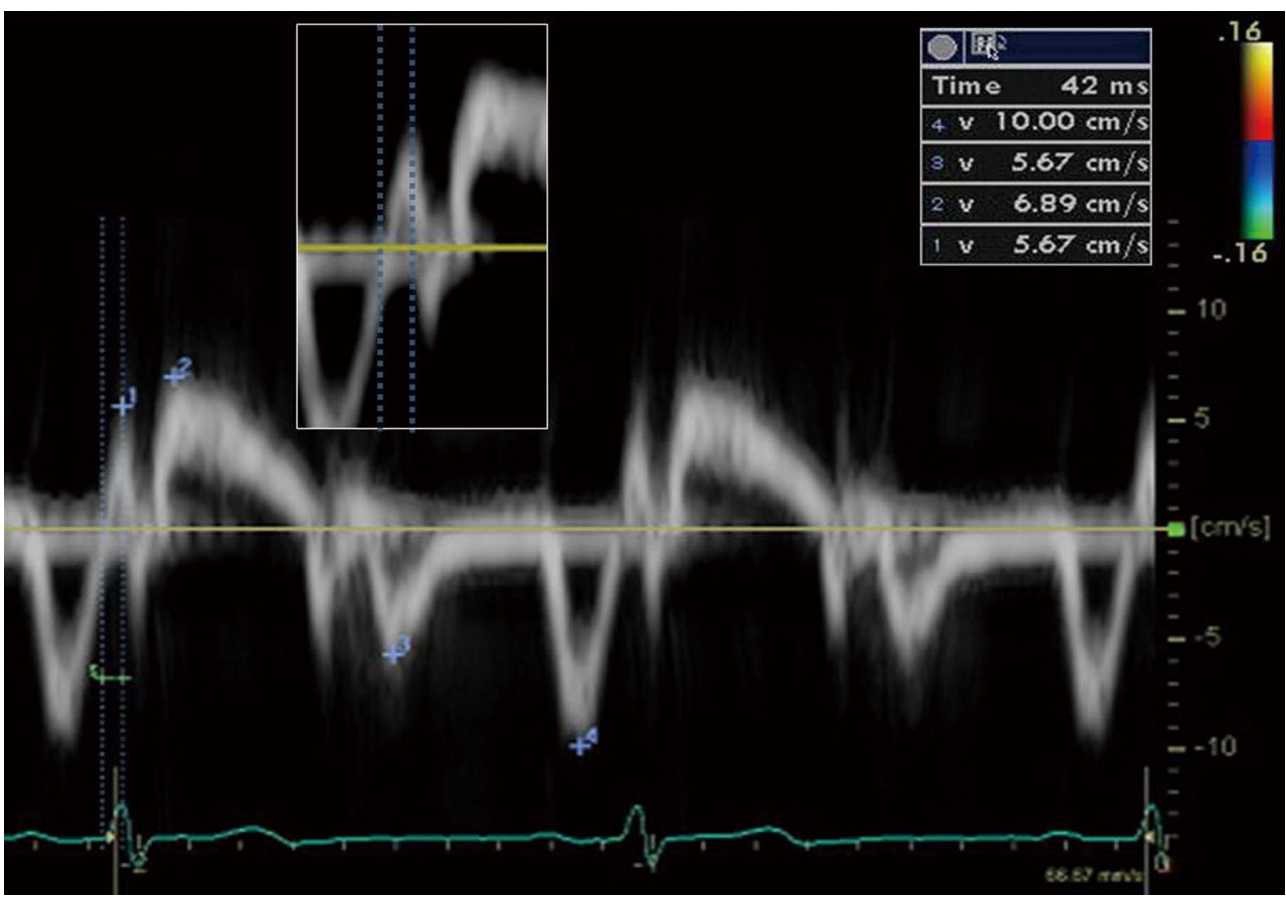

Figure 1. Spectral pulsed-wave Doppler-derived parameters obtained from the septal mitral annulus.

measured using pulsed-wave Doppler recording. The pulsedwave Doppler-derived pulmonary venous velocities were also obtained from the apical 4-chamber view. The systolic wave velocity (PV-S), early diastolic wave velocity (PV-D), and atrial contraction reverse wave velocity (PV-Ar) and the D-wave deceleration time (PV D-DcT) were measured using pulsed-wave Doppler recording. Spectral pulsed-wave tissue Doppler-derived peak systolic velocity ( $\left.\mathrm{s}^{\prime}\right)$, early diastolic velocity ( $\left.\mathrm{e}^{\prime}\right)$, late diastolic velocity (a'), as well as IC velocity (IVV), were obtained from the septal mitral annulus (Figure 1). Myocardial acceleration during IC (ie, IVA) was measured as IVV divided by isovolumetric acceleration time (IVAT), which was defined as the time spent in milliseconds from baseline to peak IC velocity (Figure 1). The onset of the IVAT was determined as the start of the upstroke of the IVV wave from the baseline using image zooming. All measurements made during IC were taken from the positive wave only. The E/e' ratio was calculated to estimate the LV filling pressure for all patients. Finally, the ratios IVV/s' and IVA/s' $\mathrm{s}^{\prime}$ were calculated to study the relation between both phases of systole and their combined effect on PCWP.

\section{Cardiac Catheterization Studies}

Cardiac catheterization was performed within $0.94 \pm 2.2$ days of the echocardiographic examination. All catheter measurements were done by an investigator blinded to the echocardiographic data. All patients underwent right-heart catheterization for hemodynamic measurements using a fluid-directed balloon tipped catheter. Stroke volume was measured using either the Fick's principle or the thermodilution method. The thermodilution method was obtained by averaging 3 cardiac cycles with less than $10 \%$ variation. Fluoroscopically verified mean PCWP, right atrial, pulmonary artery and RV pressures were obtained at end expiration with the zero-level set at the midaxillary line and represent the average of 5 cardiac cycles. LV catheter-derived peak systolic pressure (LVSP), minimal diastolic pressure (LVMDP), and end-diastolic pressure (LVEDP) were also available for 65 patients ( 21 with $\mathrm{EF} \geq 55 \%$, and 44 with $\mathrm{EF}<55 \%$ ). The intracavitary LV pressures were measured using a fluid-filled pigtail catheter attached to a pressure transducer after adjusting the zero-level as described before.

\section{Statistical Analysis}

All data are expressed as mean \pm SD. The independent sample t-test was used to compare the mean values of different groups. Linear regression was used for correlation analyses, which were expressed as Pearson correlation coefficients between all echocardiographic variables and the invasively measured PCWP. For analysis of the independent determinants of PCWP, we used a multivariate linear regression analysis model based on stepwise selection. Receiver-operator characteristics curve (ROC) was used to test the sensitivity and specificity for the detection of PCWP $\geq 15 \mathrm{mmHg}$. The intraclass correlation coefficient was then used to determine inter- and intraobserver reproducibility. For all tests, $\mathrm{P}<0.05$ was considered statistically significant. All the analyses were performed with commercially available software (SPSS version 16.0; SPSS, Inc, Chicago, IL, USA). The authors had full access to the data and take full responsibility for their integrity.

\section{Results}

Table 2 lists the echocardiographic and catheterization data for all patients, as well as for the 2 groups of patients classified

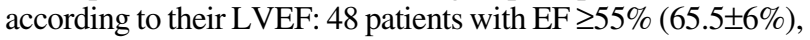
and 65 patients with EF $<55 \%(36.4 \pm 11.7 \%)$. The E-DcT, $\mathrm{a}^{\prime}$, $\mathrm{s}^{\prime}, \mathrm{PV}-\mathrm{S}$, and PV-Ar, and stroke volume were significantly lower in patients with $\mathrm{EF}<55 \%$. Other echocardiographic and catheter-derived variables were similar for both groups. 


\begin{tabular}{|c|c|c|c|c|}
\hline & $\begin{array}{c}\text { All patients } \\
(n=113)\end{array}$ & $\begin{array}{l}\text { Patients with EF } \\
\geq 55 \%(n=48)\end{array}$ & $\begin{array}{c}\text { Patients with EF } \\
<55 \%(n=65)\end{array}$ & $P$ value \\
\hline EF (\%) & $49 \pm 17$ & $66 \pm 6$ & $36 \pm 12$ & $<0.01$ \\
\hline$E(\mathrm{~cm} / \mathrm{s})$ & $76 \pm 29$ & $78 \pm 29$ & $75 \pm 29$ & 0.60 \\
\hline$A(\mathrm{~cm} / \mathrm{s})^{*}$ & $75 \pm 25$ & $80 \pm 26$ & $70 \pm 24$ & 0.06 \\
\hline$E / A^{*}$ & $1.06 \pm 0.59$ & $1.04 \pm 0.50$ & $1.08 \pm 0.68$ & 0.77 \\
\hline E-DcT (ms) & $211 \pm 80$ & $235 \pm 91$ & $193 \pm 66$ & 0.006 \\
\hline $\mathrm{e}^{\prime}(\mathrm{cm} / \mathrm{s})$ & $5.6 \pm 1.9$ & $5.9 \pm 2.1$ & $5.4 \pm 1.7$ & 0.18 \\
\hline$a^{\prime}(\mathrm{cm} / \mathrm{s})$ & $8.0 \pm 2.4$ & $8.9 \pm 2.2$ & $7.2 \pm 2.2$ & 0.001 \\
\hline IVV (cm/s) & $5.6 \pm 1.7$ & $5.9 \pm 1.5$ & $5.4 \pm 1.9$ & 0.10 \\
\hline IVAT (ms) & $32.5 \pm 8.8$ & $32.9 \pm 9.9$ & $32.1 \pm 7.9$ & 0.64 \\
\hline $\mathrm{s}^{\prime}(\mathrm{cm} / \mathrm{s})$ & $5.7 \pm 1.7$ & $6.6 \pm 1.9$ & $5.0 \pm 1.3$ & $<0.0001$ \\
\hline IVA $\left(\mathrm{m} / \mathrm{s}^{2}\right)$ & $1.80 \pm 0.59$ & $1.9 \pm 0.55$ & $1.73 \pm 0.62$ & 0.20 \\
\hline IVV/s' & $1.04 \pm 0.36$ & $0.95 \pm 0.31$ & $1.10 \pm 0.38$ & 0.01 \\
\hline IVA/s' $\left(\mathrm{s}^{-1}\right)$ & $34 \pm 13$ & $31 \pm 11$ & $36 \pm 14$ & 0.02 \\
\hline$E / e^{\prime}$ & $14.2 \pm 5.9$ & $13.9 \pm 6.0$ & $14.3 \pm 5.9$ & 0.80 \\
\hline PV-S (cm/s) & $48 \pm 17$ & $56 \pm 17$ & $43 \pm 16$ & 0.001 \\
\hline PV-D (cm/s) & $47 \pm 16$ & $50 \pm 16$ & $45 \pm 15$ & 0.08 \\
\hline PV D-DcT (ms) & $242 \pm 76$ & $257 \pm 83$ & $231 \pm 69$ & 0.07 \\
\hline PV-S/D & $1.13 \pm 0.49$ & $1.23 \pm 0.47$ & $1.05 \pm 0.49$ & 0.06 \\
\hline $\operatorname{PV}-\operatorname{Ar}(\mathrm{cm} / \mathrm{s})^{*}$ & $29 \pm 11$ & $33 \pm 14$ & $27 \pm 7$ & 0.01 \\
\hline PCWP (mmHg) & $11.2 \pm 6.8$ & $9.9 \pm 4.7$ & $12.3 \pm 7.8$ & 0.07 \\
\hline PAP $(\mathrm{mmHg})$ & $21 \pm 11$ & $21 \pm 10$ & $21 \pm 11$ & 0.97 \\
\hline $\mathrm{RVSP}(\mathrm{mmHg})$ & $36 \pm 16$ & $38 \pm 18$ & $35 \pm 15$ & 0.37 \\
\hline RVEDP (mmHg) & $6.7 \pm 5.6$ & $6.7 \pm 5.3$ & $6.7 \pm 5.8$ & 0.98 \\
\hline $\mathrm{RAP}(\mathrm{mmHg})$ & $3.6 \pm 4.3$ & $3.6 \pm 3.7$ & $3.6 \pm 4.7$ & 1.00 \\
\hline SV (ml) & $66 \pm 25$ & $73 \pm 31$ & $61 \pm 19$ & 0.02 \\
\hline LVSP'$^{\dagger}$ & $134 \pm 36$ & $140 \pm 37$ & $131 \pm 36$ & 0.40 \\
\hline LVMDP $^{\dagger}$ & $4.5 \pm 8.4$ & $1.7 \pm 3.2$ & $5.6 \pm 9.5$ & 0.09 \\
\hline LVEDP' & $14.5 \pm 6.3$ & $13 \pm 6.5$ & $15 \pm 6.1$ & 0.24 \\
\hline
\end{tabular}

${ }^{*} \mathrm{~A}, \mathrm{E} / \mathrm{A}$, and PV-Ar were assessed in a subset of 92 patients with sinus rhythm. +LVSP, LVMDP, and LVEDP were calculated in 65 cases ( 21 with $E F \geq 55 \%$ and 44 with $E F<55 \%$ ).

$\mathrm{EF}$, ejection fraction; E, early diastolic mitral flow velocity; A, late diastolic mitral flow velocity; E-DcT, early diastolic mitral flow deceleration time; $e^{\prime}$, TDI-derived septal mitral annular early diastolic velocity; a', TDI-derived septal mitral annular late diastolic velocity; IVV, isovolumetric contraction velocity; IVAT, isovolumetric acceleration time; s', TDIderived septal mitral annular systolic velocity; IVA, isovolumetric acceleration; PV-S, pulmonary venous systolic wave velocity; PV-D, pulmonary venous diastolic wave velocity; PV D-DcT, pulmonary venous D-wave deceleration time; $\mathrm{PV}-\mathrm{S} / \mathrm{D}$, ratio between pulmonary venous $\mathrm{S}$ and $\mathrm{D}$ velocities; PV-Ar, pulmonary venous reverse atrial wave velocity; PCWP, pulmonary capillary wedge pressure; PAP, pulmonary artery pressure; RVSP, right ventricular systolic pressure; RVEDP, right ventricular end-diastolic pressure; RAP, right atrial pressure; SV, stroke volume; LVSP, left ventricular systolic pressure; LVMDP, left ventricular minimal diastolic pressure; LVEDP, left ventricular end-diastolic pressure.

\section{Overall Correlations Between Echocardiographic Parameters and PCWP}

For all patients, significant correlations were found between PCWP and the isovolumetric variables, IVV and IVA $(\mathrm{r}=-0.48$, -0.54 , respectively; $\mathrm{P}<0.0001$ ), as well as the diastolic variables, E/A and $\mathrm{E} / \mathrm{e}^{\prime}$ ( $\mathrm{r}=0.48,0.51$, respectively; $\left.\mathrm{P}<0.0001\right)$. Weaker correlations were found for PV D-DcT and PV-S/D ( $\mathrm{r}=-0.28, \mathrm{P}=0.007$; and $\mathrm{r}=-0.38, \mathrm{P}<0.0001$, respectively). The systolic parameters, EF and $\mathrm{s}^{\prime}$, did not correlate with PCWP $(\mathrm{r}=-0.17, \mathrm{P}=0.13$ and $\mathrm{r}=-0.1, \mathrm{P}=0.18$, respectively $)$.

\section{Comparison of Patients With Preserved and Reduced LVEF}

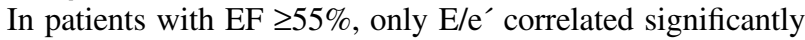
with the invasively measured PCWP $(\mathrm{r}=-0.58, \mathrm{P}<0.0001)$, whereas IVV and IVA did not $(\mathrm{r}=-0.25,-0.08$ and $\mathrm{P}=0.08$, 0.58; respectively) (Figure 2, Table 3). In patients with EF $<55 \%$, on the other hand, both IVV and IVA correlated significantly with PCWP $(\mathrm{r}=-0.55,-0.72$, and $\mathrm{P}<0.0001$; respectively) (Figure 2, Table 3). Other variables that showed sig- nificant correlations with $\mathrm{PCWP}$ in this group of patients were $\mathrm{E} / \mathrm{A}(\mathrm{r}=0.61, \mathrm{P}<0.0001), \mathrm{E} / \mathrm{e}^{\prime}(\mathrm{r}=0.51, \mathrm{P}<0.0001)$, PV D-DcT $(\mathrm{r}=-0.38, \mathrm{P}=0.002)$, and $\mathrm{PV}-\mathrm{S} / \mathrm{D}(\mathrm{r}=-0.44, \mathrm{P}<0.0001)$. Of note, EF and $s^{\prime}$ did not show any correlation with PCWP in either group.

\section{Relation Between Both Phases of Systole and Its Effect on PCWP}

The ratios IVV/s' and IVA/s' were calculated for all patients to study the relation between the tissue Doppler-derived myocardial velocities of both the isovolumetric and ejection phases of contraction. Unlike IVV and IVA, both ratios were significantly higher in patients with $\mathrm{EF}<55 \%$ (IVV/s': $0.95 \pm 0.31$ vs. $1.1 \pm 0.38, \mathrm{P}=0.01 ; \mathrm{IVA} / \mathrm{s}^{\prime}: 31 \pm 11$ vs. $34 \pm 13 \mathrm{~s}^{-1}, \mathrm{P}=0.02$; Table 2). As for IVV and IVA, both ratios correlated well with PCWP in patients with EF $<55 \%$ (IVV/s' $: r=-0.50$, IVA/s': $\mathrm{r}=-0.61, \mathrm{P}<0.0001)$, but not in patients with $\mathrm{EF} \geq 55 \%$ (Table 3). Suggested by their overall means and by ROC curve, as discussed later, a cut value of 1 in the case of IVV/s' and of 


\section{(A) Overall Patients}

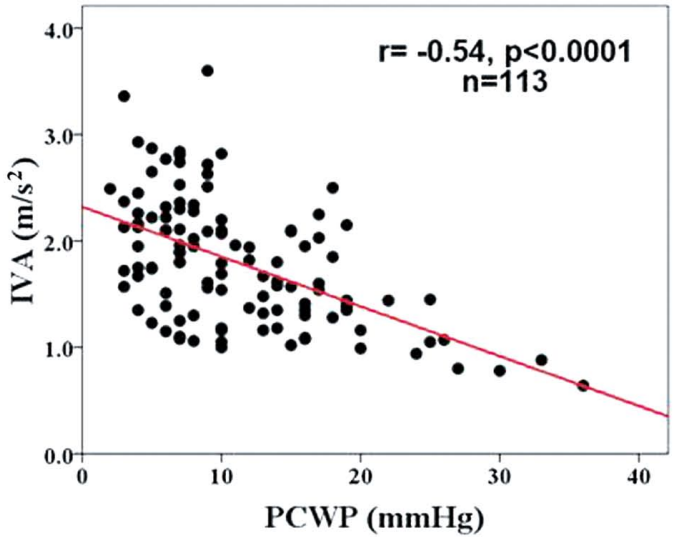

(B) Patients with EF $\geq 55 \%$

(C) Patients with EF $<55 \%$
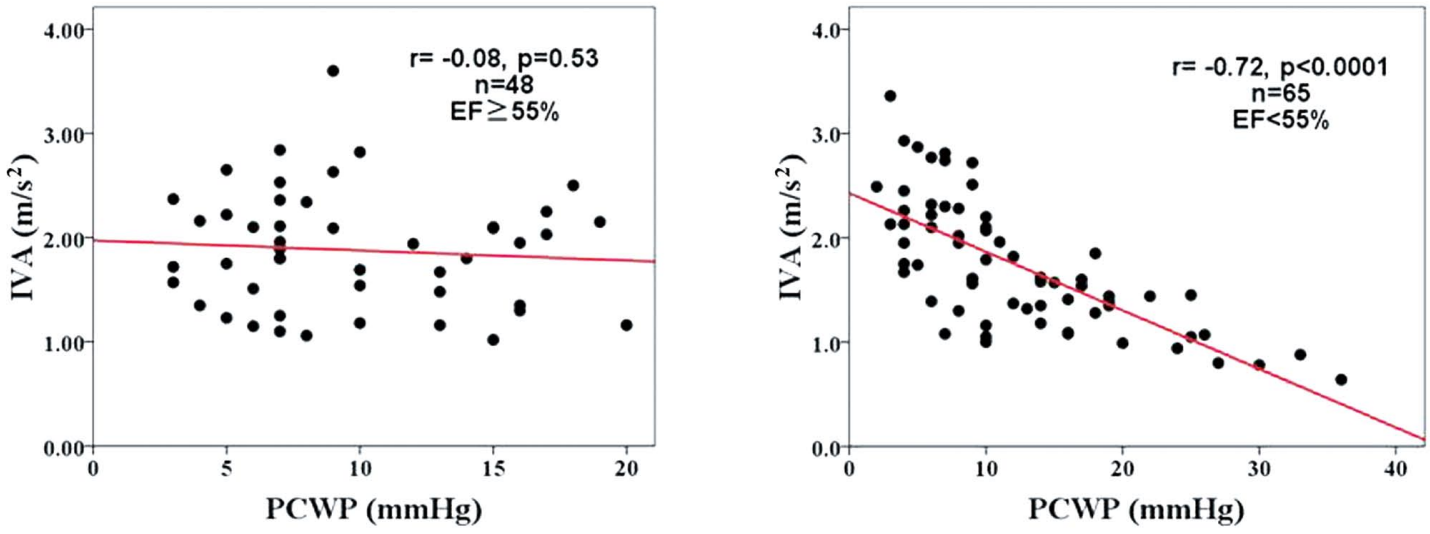

Figure 2. Dot plots of isovolumetric acceleration (IVA) in relation to pulmonary capillary wedge pressure (PCWP) for all patients (A), patients with ejection fraction $(E F) \geq 55 \%(B)$ and patients with $E F<55 \%(C)$. IVA correlated significantly with PCWP for all patients and patients with EF $<55 \%$, but such a correlation was not observed for patients with EF $\geq 55 \%$.

\begin{tabular}{|c|c|c|c|c|c|c|c|c|c|}
\hline & \multirow{2}{*}{\multicolumn{2}{|c|}{$\begin{array}{c}\text { All Patients }(n=113) \\
\text { Linear regression }\end{array}$}} & \multirow{2}{*}{\multicolumn{2}{|c|}{$\begin{array}{c}\text { Patients with EF } \\
\geq 55 \%(n=48)\end{array}$}} & \multicolumn{5}{|c|}{ Patients with EF $<55 \%(n=65)$} \\
\hline & & & & & \multicolumn{2}{|c|}{ Linear regression } & \multicolumn{3}{|c|}{ Multivariate regression model Adjusted $\mathrm{r}^{2}=0.64$} \\
\hline & $\mathbf{r}$ & $P$ value & $\mathbf{r}$ & $P$ value & $\mathbf{r}$ & $P$ value & $\beta$ coefficient & $95 \% \mathrm{Cl}$ & $P$ value \\
\hline IVA $\left(\mathrm{m} / \mathrm{s}^{2}\right)$ & -0.54 & $<0.0001$ & -0.08 & 0.58 & -0.72 & $<0.0001$ & -0.44 & -9.36 to -3.95 & $<0.0001$ \\
\hline $\operatorname{IVV}(\mathrm{cm} / \mathrm{s})$ & -0.48 & $<0.0001$ & -0.25 & 0.08 & -0.55 & $<0.0001$ & -0.121 & -0.168 to 0.67 & 0.395 \\
\hline IVV/s' & -0.35 & $<0.0001$ & -0.17 & 0.26 & -0.50 & $<0.0001$ & -0.021 & -23.9 to 23.07 & 0.969 \\
\hline IVA/s' $\left(\mathrm{s}^{-1}\right)$ & -0.40 & $<0.0001$ & -0.08 & 0.59 & -0.61 & $<0.0001$ & -0.147 & -24.9 to 7.5 & 0.287 \\
\hline$E / A$ & 0.48 & $<0.0001$ & 0.14 & 0.36 & 0.61 & $<0.0001$ & 0.35 & 1.74 to 6.32 & 0.001 \\
\hline$E / e^{\prime}$ & 0.51 & $<0.0001$ & 0.58 & $<0.0001$ & 0.51 & $<0.0001$ & 0.106 & -0.155 to 0.457 & 0.324 \\
\hline PV-S/D & -0.38 & $<0.0001$ & -0.17 & 0.27 & -0.44 & $<0.0001$ & 0.063 & -2.78 to 4.78 & 0.596 \\
\hline PV D-DcT (ms) & -0.28 & 0.007 & -0.03 & 0.87 & -0.38 & 0.002 & -0.26 & -0.57 to -0.009 & 0.009 \\
\hline EF (\%) & -0.17 & 0.1 & -0.22 & 0.13 & -0.01 & 0.94 & - & - & - \\
\hline $\mathrm{s}^{\prime}(\mathrm{cm} / \mathrm{s})$ & -0.13 & 0.18 & 0.01 & 0.95 & -0.08 & 0.52 & - & - & - \\
\hline
\end{tabular}

All abbreviations as in Table 2 . 
Table 4. PCWP Values for Patients Classified According to Their EF, IVV/s', and IVA/s' Values

\begin{tabular}{|c|c|c|c|c|c|c|c|c|c|c|}
\hline & \multicolumn{2}{|c|}{ IVV/s' $\geq 1$} & \multicolumn{2}{|c|}{ IVV/s' $<1$} & \multirow{2}{*}{$P$ value } & \multicolumn{2}{|c|}{ IVA/s' $\geq 34$} & \multicolumn{2}{|c|}{ IVA/s' $<34$} & \multirow{2}{*}{$P$ value } \\
\hline & $\mathbf{n}$ & Mean & $n$ & Mean & & $\mathbf{n}$ & Mean & $\mathrm{n}$ & Mean & \\
\hline$E F \geq 55 \%$ & 20 & $8.8 \pm 4.4$ & 28 & $10.3 \pm 4.8$ & 0.26 & 15 & $9.33 \pm 4.8$ & 33 & $9.8 \pm 4.7$ & 0.75 \\
\hline$E F<55 \%$ & 35 & $9.8 \pm 6.0$ & 30 & $15.4 \pm 8.7$ & 0.003 & 33 & $8.7 \pm 4.8$ & 32 & $16.2 \pm 8.7$ & $<0.0001$ \\
\hline
\end{tabular}

PCWP, pulmonary capillary wedge pressure. Other abbreviations as in Table 2.

\begin{tabular}{|c|c|c|c|c|c|c|c|}
\hline & \multicolumn{3}{|c|}{ All Patients classified according to PCWP } & \multicolumn{4}{|c|}{$\begin{array}{l}\text { Patients with EF }<55 \% \text { classified } \\
\text { according to E/e' (dependent: PCWP) }\end{array}$} \\
\hline & \multirow{2}{*}{$\begin{array}{c}\begin{array}{c}\text { Group A (PCWP } \\
<15 \mathrm{mmHg})(\mathrm{n}=81)\end{array} \\
\text { Mean } \pm \text { SD }\end{array}$} & \multirow{2}{*}{$\begin{array}{c}\text { Group B (PCWP } \\
\geq \frac{15 \mathrm{mmHg})(\mathrm{n}=32)}{M e a n \pm S D}\end{array}$} & \multirow[b]{2}{*}{$P$ value } & \multicolumn{2}{|c|}{$\begin{array}{c}E / e^{\prime}<8 \text { or }>15 \\
(n=34)\end{array}$} & \multicolumn{2}{|c|}{$\begin{array}{l}\text { E/e' between } 8 \\
\text { and } 15(n=31)\end{array}$} \\
\hline & & & & r value & $P$ value & $r$ value & $P$ value \\
\hline $\operatorname{IVV}(\mathrm{cm} / \mathrm{s})$ & $5.97 \pm 1.7$ & $4.65 \pm 1.44$ & $<0.0001$ & 0.63 & $<0.0001$ & 0.33 & 0.06 \\
\hline IVA $\left(\mathrm{m} / \mathrm{s}^{2}\right)$ & $1.94 \pm 0.57$ & $1.42 \pm 0.47$ & $<0.0001$ & 0.74 & $<0.0001$ & 0.59 & $<0.0001$ \\
\hline $\mathrm{IVV} / \mathrm{s}^{\prime}$ & $1.1 \pm 0.36$ & $0.88 \pm 0.32$ & 0.003 & 0.53 & 0.001 & 0.45 & 0.01 \\
\hline IVA/s' $\left(s^{-1}\right)$ & $36 \pm 13$ & $27 \pm 10$ & $<0.0001$ & 0.59 & $<0.0001$ & 0.59 & 0.001 \\
\hline$E / e^{\prime}$ & $12.2 \pm 3.9$ & $19.12 \pm 7.07$ & $<0.0001$ & 0.57 & $<0.0001$ & 0.04 & 0.83 \\
\hline$E / A$ & $0.94 \pm 0.43$ & $1.44 \pm 0.83$ & $<0.0001$ & - & - & - & - \\
\hline PV D-DcT (ms) & $250 \pm 72$ & $222 \pm 81$ & 0.08 & - & - & - & - \\
\hline $\mathrm{PV} \mathrm{S} / \mathrm{D}$ & $1.21 \pm 0.49$ & $0.89 \pm 0.45$ & 0.005 & - & - & - & - \\
\hline $\mathrm{s}^{\prime}(\mathrm{cm} / \mathrm{s})$ & $5.7 \pm 1.7$ & $5.6 \pm 1.93$ & 0.72 & - & - & - & - \\
\hline $\mathrm{EF}(\%)$ & $49.6 \pm 18$ & $46.7 \pm 15.7$ & 0.44 & - & - & - & - \\
\hline
\end{tabular}

All abbreviations as in Tables 2,4.

$34 \mathrm{~s}^{-1}$ in the case of IVA/s' were used to test differences between PCWP values in subgroups (Table 4). Among the patients with $\mathrm{EF}<55 \%, 35$ had an IVV/s' value $\geq 1$, and 30 had IVV/s' value $<1$. The PCWP for patients with IVV/s' $<1$ was significantly higher than in those with IVV/s' $\geq 1(15.4 \pm$ $8.7 \mathrm{mmHg}, 9.8 \pm 6.0 \mathrm{mmHg}$, respectively; $\mathrm{P}=0.003$ ). Similarly, in the same group of patients, $33 \mathrm{had}$ IVA/ $\mathrm{s}^{\prime} \geq 0.34 \mathrm{~s}^{-1}$ and 32 had IVA $/ \mathrm{s}^{\prime}<0.34 \mathrm{~s}^{-1}$, and the PCWP was significantly higher in patients with IVA/s' $<0.34 \mathrm{~s}^{-1}(16.2 \pm 8.7 \mathrm{mmHg}$, $8.7 \pm 4.8 \mathrm{mmHg}, \mathrm{P}<0.0001)$. The same classification for cases with EF $\geq 55 \%$ failed to show any significant difference between PCWP values.

\section{Independent Predictors of PCWP}

For patients with $\mathrm{EF}<55 \%$, multivariate linear regression showed that IVA $(\beta=-0.44, P<0.0001), E / A$ ratio $(\beta=0.35$, $\mathrm{P}=0.001)$, and D-DcT $(\beta=-0.26, \mathrm{P}=0.009)$ were independent determinants of PCWP (Table 3). Despite that E/e' showed a comparable correlation with PCWP in this group ( $\mathrm{r}=0.51$, $\mathrm{P}<0.0001)$, it was excluded from the multivariate model $(\beta=0.106, \mathrm{P}=0.324)$.

\section{Detection of PCWP $\geq 15 \mathrm{mmHg}$}

Next, patients were classified into 2 groups according to their PCWP. Group A consisted of 81 patients with PCWP $<15 \mathrm{mmHg}$ and Group B of 32 patients with PCWP $\geq 15 \mathrm{mmHg}$ (Table 5). The diastolic parameters were significantly different for both groups, as Group B showed a higher E/A ratio (1.44 \pm 0.83 vs. $0.94 \pm 0.43, \mathrm{P}<0.0001)$, higher $\mathrm{E} / \mathrm{e}^{\prime}$ ratio $(19.12 \pm 7.07$ vs. $12.2 \pm$ $3.9, \mathrm{P}<0.0001)$, lower $\mathrm{PV}-\mathrm{S} / \mathrm{D}$ ratio $(0.89 \pm 0.45$ vs. $1.21 \pm 0.49$, $\mathrm{P}=0.005)$ and slightly shorter PV D-DcT (222 \pm 81 vs. $250 \pm 72 \mathrm{~ms}$, $\mathrm{P}=0.08$ ). Furthermore, patients in Group B showed significantly lower isovolumetric systolic parameters (IVV: $4.65 \pm 1.44$ vs. $5.97 \pm 1.7, \mathrm{P}<0.0001$; IVA: $1.42 \pm 0.47$ vs. $1.94 \pm 0.57, \mathrm{P}<0.0001)$, and significantly lower IVV/s' and IVA/s' (IVV/s': $0.88 \pm 32$ vs.
$1.1 \pm 0.36, \mathrm{P}=0.003$; IVA/s': $27 \pm 10$ vs. $36 \pm 13, \mathrm{P}<0.0001$, respectively), but EF and $\mathrm{s}^{\prime}$ were not different between both groups.

The ROC curve was initiated for IVA, IVV, IVA/s', IVV/s', and $\mathrm{E} / \mathrm{A}$ in patients with $\mathrm{EF}<55 \%$. It was found that IVA of $1.60 \mathrm{~m} / \mathrm{s}^{2}$ and IVV of $4.95 \mathrm{~cm} / \mathrm{s}$ had sensitivities of $95 \%$ and $71 \%$, respectively; and specificities of $73 \%$ and $64 \%$, respectively, for predicting PCWP $\geq 15 \mathrm{mmHg}$ (IVV: area under the curve $[\mathrm{AUC}]=0.758,95 \%$ confidence interval $[\mathrm{CI}] 0.632-$ $0.884, \mathrm{P}=0.001$; IVA: $\mathrm{AUC}=0.867$, 95\%CI 0.782-0.952, $\mathrm{P}<0.0001$, Figure 3A). The E/A value of 0.94 was $83 \%$ sensitive and $67 \%$ specific for detecting PCWP $>15 \mathrm{mmHg}$ in this subset of patients (AUC $=0.778,95 \% \mathrm{CI} 0.633-0.923, \mathrm{P}=0.004$, Figure 3B). In the case of IVV/s' ${ }^{\prime}$ and IVA/s' in patients with $\mathrm{EF}<55 \%$, the ROC curve suggested that an IVV/s' value of 1 and an IVA/s' value of $34 \mathrm{~s}^{-1}$ could effectively predict PCWP $\geq 15 \mathrm{mmHg}$ with sensitivities of $71 \%$ and $76 \%$, and specificities of $60 \%$ and $64 \%$, respectively (IVV/s': AUC $=0.74,95 \% \mathrm{CI}$ $0.606-0.868, \mathrm{P}=0.002 ; \mathrm{IVA} / \mathrm{s}^{\prime}: \mathrm{AUC}=0.84$, 95\%CI $0.723-$ $0.95, \mathrm{P}<0.0001$, Figure 3A).

\section{Advantage of IVA Over $\mathrm{E} / \mathrm{A}$ and $\mathrm{E} / \mathrm{e}^{\prime}$}

Of the 65 patients in this study with $\mathrm{EF}<55 \%, 16$ had $\mathrm{AF}$ : 7 of them had PCWP $<15 \mathrm{mmHg}(11.6 \pm 2.3)$, and 9 had PCWP $\geq 15 \mathrm{mmHg}$ (21.1 \pm 6.7$)$. The correlation between IVA and PCWP for those patients was preserved $(r=0.63, \mathrm{P}<0.0001)$. In this subset of patients, we noticed that a correlation with PCWP was only obtained in cases of IVV and IVA, and none of the other variables showed a correlation with PCWP. It is worth noting that the E/ $\mathrm{e}^{\prime}$ ratio in these patients showed a moderate correlation that lost statistical significance, which might be because of the small number of patients. Finally, to confirm the previously noticed superiority of IVA over E/e' for patients with $\mathrm{EF}<55 \%$, these patients were classified according to their E/e' value into 2 groups, the first group consisting of 34 patients with E/e' values less than 8 or more than 


\section{ROC curves in patients with EF $<55 \%$}

(A) IVV, IVA, IVV/s', and IVA/s'

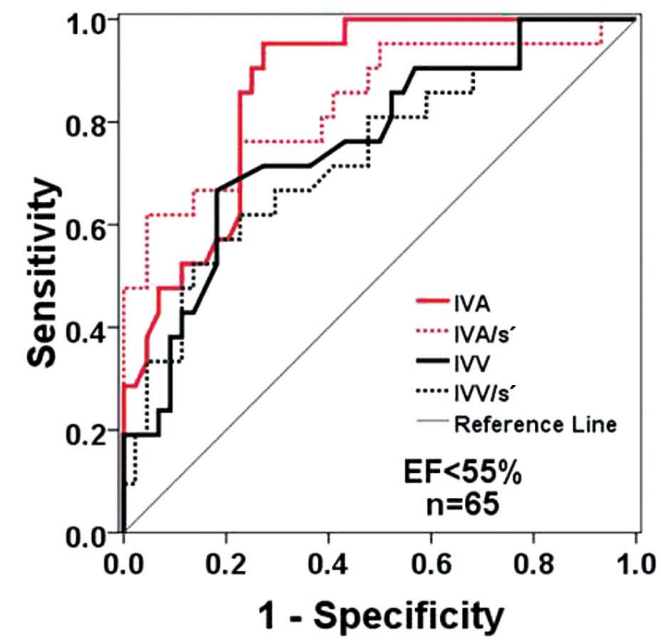

(B) $E / A$

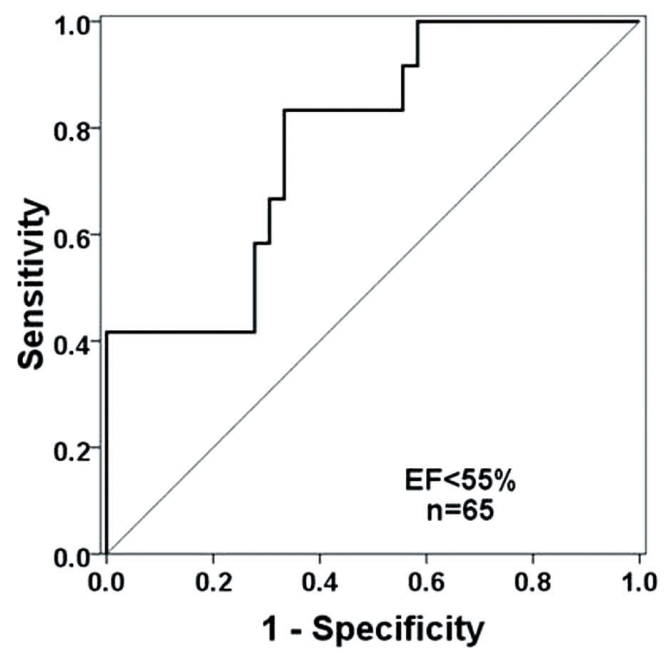

Figure 3. Receiver-operating characteristics $(\mathrm{ROC})$ curve analysis for predicting pulmonary capillary wedge pressure $\geq 15 \mathrm{mmHg}$ in patients with ejection fraction (EF) $<55 \%$. (A) Isovolumetric contraction velocity (IVV) of $4.95 \mathrm{~cm} / \mathrm{s}$ showed a sensitivity of $58 \%$ and a specificity of $75 \%$, and the corresponding values for isovolumetric acceleration (IVA) of $1.59 \mathrm{~cm} / \mathrm{s}^{2}$ were $92 \%$ and $83 \%$; respectively. E/A did not show statistically significant results. (B) IVV/s' value of 1 showed a sensitivity of $71 \%$ and a specificity of $60 \%$, and the corresponding values for IVA/s' of $34 \mathrm{~s}^{-1}$ were $76 \%, 64 \%$; respectively.

15 , and the second group of 31 patients with E/e' values between 8 and 15 ( $\geq 8$ and $\leq 15)$. It was noticed that both IVA and E/e' correlated significantly with PCWP for patients with E/e' less than 8 or more than 15 ( $\mathrm{r}=0.74$ and 0.57 , respectively; $\mathrm{P}<0.0001$, Table 5). However, in patients with $\mathrm{E} / \mathrm{e}^{\prime}$ values between 8 and 15, IVA correlated with PCWP and the correlation with the $\mathrm{E} / \mathrm{e}^{\prime}$ was lost $(\mathrm{r}=0.59,0.04, \mathrm{P}<0.0001,=0.83$, respectively, Table 5).

\section{Comparison With LVEDP}

Besides correlating with PCWP, IVA showed a statistically significant correlation with LVEDP in patients with $\mathrm{EF}<55 \%$ $(\mathrm{r}=0.4, \mathrm{P}=0.01)$. Again, this correlation was not noticed in patients with $\mathrm{EF} \geq 55 \%$ ( $\mathrm{r}=0.23, \mathrm{P}=0.33)$. Of note, the LVEDP showed a good overall correlation with PCWP ( $\mathrm{r}=0.61$, $\mathrm{P}<0.0001)$ and the correlation was maintained for patients with $\mathrm{EF} \geq 55 \%$ or $\mathrm{EF}<55 \%$ ( $\mathrm{r}=0.61$ and $0.62 ; \mathrm{P}=0.006$ and $<0.0001$, respectively).

\section{Other Determinants of IVV and IVA}

Several echocardiographic variables correlated with IVV and IVA, but the correlations were almost always found only in patients with $\mathrm{EF}<55 \%$. Left atrial volume (LAV), s', a', E, E/A, E/e', PV-S, PV-D, and PV-S/D correlated with IVV and IVA in patients with $\mathrm{EF}<55 \%$. Multivariate linear regression analysis of patients with EF $<55 \%$ revealed that only PCWP and $\mathrm{s}^{\prime}$ could independently predict IVV (adjusted $\mathrm{r}^{2}=0.409, \beta$ : $-0.444,0.454, \mathrm{P}=0.001$, respectively), whereas PCWP and $\mathrm{a}^{\prime}$ could independently predict IVA (adjusted $\mathrm{r}^{2}=0.555, \beta:-0.586$, $0.301, \mathrm{P}<0.0001,=0.037$, respectively). All previously mentioned echocardiographic variables correlated with IVV and
IVA only in patients with EF $<55 \%$, except for s', E/A and E/e', which correlated with IVV in both patients with EF $\geq 55 \%$ and those with $\mathrm{EF}<55 \%$; multivariate regression analysis showed that only E/e' could independently predict IVV in such cases (adjusted $\mathrm{r}^{2}=0.269, \beta$ : 0.535, $\mathrm{P}<0.0001$ ). Finally, no echocardiographic variable correlated with IVA in patients with $\mathrm{EF} \geq 55 \%$.

\section{Reproducibility}

The intraclass correlation coefficients for interobserver reproducibility of IVV and IVA were 0.944 (mean difference= $0.34 \pm 0.54 \mathrm{~cm} / \mathrm{s}, 95 \%$ CI $0.761-0.919, \mathrm{P}<0.0001)$ and 0.89 (mean difference $=0.2 \pm 0.25 \mathrm{~m} / \mathrm{s}^{2}, 95 \% \mathrm{CI} 0.826-0.946, \mathrm{P}<0.0001$ ), respectively, and the respective intraclass correlation coefficients for intraobserver reproducibility of IVV and IVA were 0.934 (mean difference $=0.29 \pm 0.64 \mathrm{~cm} / \mathrm{s}, 95 \% \mathrm{CI} 0.878-0.956$, $\mathrm{P}<0.0001$ ) and 0.91 (mean difference $=0.1 \pm 0.29 \mathrm{~m} / \mathrm{s}^{2}, 95 \% \mathrm{CI}$ $0.838-0.953, \mathrm{P}<0.0001)$, respectively.

\section{Discussion}

This study demonstrated that TDI-derived IVA of the septal mitral annulus, despite not correlating with PCWP in patients with preserved systolic function, correlated well and independently predicted PCWP, and was better than other echocardiographic predictors in patients with systolic dysfunction, probably because it compensates for the ejection systolic dysfunction in patients with systolic HF.

\section{Physiological Aspects of Isovolumetric Contraction}

Velocities recorded by TDI during IC at the mitral annulus 
show a longitudinal acceleration-deceleration pattern, the mechanism of which is not yet clear but suggests, unlike the previous understanding, a dynamic nature of IC. Whether these velocities represent myocardial deformation remains questionable. Remme et al explained this biphasic motion as an early systolic shortening that is interrupted by the longitudinal motion produced by mitral valve closure; and added that myocardial deformation does not occur during IC. ${ }^{16}$ In our study, both IVV and IVA correlated with $\mathrm{a}^{\prime}$ only in patients with EF $<55 \%$ ( $\mathrm{r}=0.35,0.55, \mathrm{P}=0.017,<0.0001$, respectively), suggesting that IVV may be related to the elastic potential energy of $\mathrm{a}^{\prime}$, which favors the findings by Remme et al. However, this does not seem enough to explain the correlations noticed in our study, especially that, again, both IVV and IVA lost such correlation with $\mathrm{a}^{\prime}$ in patients with $\mathrm{EF} \geq 55 \%$ ( $\mathrm{r}=0.043,0.15$, $\mathrm{P}=0.784$, 0.338, respectively). IC was, however, reported in other studies to be dynamic in terms of thickening because of subendocardial fiber shortening, which, because of subepicardial sheet extension and negative angle formation, is kept within the isovolumetric constraint. ${ }^{17,18}$ Thus, it seems that the biphasic (positive-negative) nature of the IVV is caused by counter-directional myocardial deformations that occur in such a fashion as to cause actual deformation without changing the LV volume. The finding that, myocardial deformation during IC occurs in all directions, including the longitudinal axis, has lead to a conclusion that mitral valve closure might not affect the mechanics during IC. Another reported dynamic aspect of IC is the brief period of myocardial untwist, which precedes the torsion (Twist) that occurs during ejection. ${ }^{19-22}$ Although variables derived from IC are reported to predict the load-independent state of contractility of both the $\mathrm{LV}$ and $\mathrm{RV},{ }^{6-11}$ the hemodynamic and clinical effects of the previously mentioned dynamic aspects are still not clear.

\section{Systolic and Diastolic Interaction and the Role of Isovolumetric Contraction}

Ventricular torsion during ejection and the subsequent early diastolic untwist are reported to interdependently affect diastolic filling because of the mechanical and timing relationships of the circular and helical muscular pathways of the myocardium. However, myocardial untwist also occurs preejection, and an understanding of IC is said to be essential to explain this systolic-diastolic interaction. ${ }^{20}$ Luo et al found that in patients with systolic $\mathrm{HF}$, myocardial untwist during IC is prolonged into the ejection phase and that torsion during ejection is also prolonged into the diastolic phase. ${ }^{23}$ Cho et al also reported that the ability of the IVV and IVA to predict the exercise capacity of patients with depressed systolic function might be explained by dynamic changes of IC that affect the force of cardiac contraction during ejection, and the timing of systolic cross-over into diastole. ${ }^{13}$ In our study, the fact that both IVV and IVA inversely correlated with PCWP (higher PCWP with lower IVV and IVA), and the preservation of such correlations after combining them with ejection systolic variables in the ratios IVV/s' and IVA/s's, supports the dynamic nature of IC and its effect on other phases of the cardiac cycle.

\section{Defining Systolic Dysfunction}

Unlike the IVV and IVA, which showed no difference between patients with and without systolic dysfunction, both IVV/s' and IVA/s' were significantly higher in patients with $\mathrm{EF}<55 \%$, despite that all isovolumetric variables (IVV, IVA, IVV/s', and IVA/s') were significantly lower in patients with

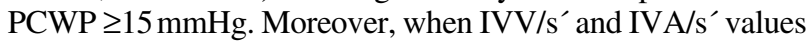
were less than 1 and $34 \mathrm{~s}^{-1}$, respectively, and PCWP was sig- nificantly higher in patients with systolic dysfunction (IVV/s': 15.4 vs. $9.8 \mathrm{mmHg}, \mathrm{P}=0.003$; IVA/s': 16.2 vs. $8.7 \mathrm{mmHg}$, $\mathrm{P}<0.0001$ ), however did not differ in patients with preserved systolic functions. Our explanation for these findings is that, as the LV goes into ejection systolic failure, patients with preserved IC values show better hemodynamics. This suggests that the previously mentioned dynamic aspects of IC are essential for appropriate systolic function, and when preserved, can compensate for the ejection systolic dysfunction. Thus, defining systolic function and the systolic-diastolic interaction only according to ejection variables (EF and s' in our study) seems insufficient.

\section{Another Possible Mechanism of Correlation}

Lindqvist et al explained the correlation noticed between RVIVA and right atrial pressure by the mechanics of the FrankStarling law; that is, as the initial sarcomere length increases at end-diastole, IVV and IVA increase as a direct result of Starling forces. ${ }^{12}$ Despite we found a similar correlation between LV-IVA and LVEDP in patients with $\mathrm{EF}<55 \%$ ( $\mathrm{r}=0.4$, $\mathrm{P}=0.01$ ), we do not think this is enough to explain why LVIVA in our study correlated with both LVEDP and PCWP only in the case of depressed systolic dysfunction ( $\mathrm{r}=0.4,0.72$, $\mathrm{P}=0.01,<0.0001$, respectively), and not in the case of preserved systolic function $(\mathrm{r}=0.08,0.23, \mathrm{P}=0.58,0.33$, respectively).

\section{Lack of Correlations in Patients With Preserved Systolic Function}

Despite that IC reportedly represents the load-independent state of contraction in many studies, a recent study by Lyseggen et al has questioned this concept when they found that loading the LV induced a marked decrease of IVA and dissociated it from contractility. ${ }^{24}$ Our ideas on the mechanism of IVV and IVA correlation are based on the untwist-torsion exhibited in IC and ejection, respectively. Changes in torsion and untwisting mechanics within the normal conical heart are reported to be load-dependent. ${ }^{19,20,25}$ Conversely, dilated and failing hearts exhibit different torsion and untwisting responses, independent of loading conditions, because cardiac fiber orientation is responsible for such rotational changes. ${ }^{20,26}$ Accordingly, the lack of correlation with PCWP in patients with preserved systolic function noticed in our study seems reasonable, and furthermore, the effect of loading reported by Lyseggen et al does not necessarily represent the situation in patients with systolic HF, because they studied animal models that had basically preserved systolic function.

\section{Clinical Implications}

The E/e' ratio is reportedly the best predictor of PCWP in patients with preserved as well as reduced systolic function. In our study, E/e' also showed acceptable correlations in both cases $(\mathrm{r}=0.58,0.51$, respectively, and $\mathrm{P}<0.0001)$, but IVA showed a stronger correlation for patients with $\mathrm{EF}<55 \%$ $(\mathrm{r}=0.72, \mathrm{P}<0.0001)$. Moreover, $\mathrm{E} / \mathrm{e}^{\prime}$ was not an independent predictor of PCWP in this group of patients, whereas IVA proved to be the best predictor. This was explained when we found, as also mentioned in previous studies, ${ }^{27-29}$ that for 31 of our patients with E/e' between 8 and 15, E/e' did not show a correlation with PCWP $(\mathrm{r}=0.04, \mathrm{P}=0.83)$, but the correlation was preserved for IVA $(\mathrm{r}=0.59, \mathrm{P}<0.0001)$. In addition, in patients with $\mathrm{EF}<55 \%$ and $\mathrm{AF}$ in our study, IVA and IVV were the only variables that correlated with PCWP.

It is important to note that IVA was the best IC predictor of PCWP, and that might denote the importance of acceleration, 
which combines both velocity and temporal changes of IC. However, despite the excellent correlation, IVA is limited by its moderate reproducibility because of TDI temporal resolution. On the other hand, IVV/s' $<1$ seems to be a simple predictor of high PCWP in patients with depressed systolic function, which represents additional information about the relation between both systolic phases. However, it lacks the temporal factor represented by IVA. For that, we still recommend echocardiographic assessment of PCWP using the well-established variables E/e' and E/A, considering IVA only as an alternative for patients with reduced systolic function who have E/e' values between 8 and 15 or AF.

\section{Study Limitations}

Unfortunately, there are several limitations. First, this study included a small number of patients in a retrospective singlecenter study, so future studies of larger patient populations are necessary to more accurately determine the utility of IVA for the evaluation of PCWP. It is worth noting that, because of being a retrospective analysis, available data was not sufficient to measure torsion and untwist during IC and as such future studies should also be concerned with measuring these variables and assessing their relation to PCWP. Second, TDI measurements are angle dependent, so the angle between the ultrasound beam and the LV axis must be kept small. In our study, the smallest possible angle $\left(<30^{\circ}\right)$ was kept during measurements of IVV and IVA. Third, although we measured the TDI-derived parameters from only the septal side of the mitral annulus, it is recommended to acquire TDI measurements from at least both the septal and lateral sides of the mitral annulus and calculate their average. ${ }^{30}$ The measurement of IC variables from the septal side only can, however, be justified, as it is reported to be the area with the best reproducibility and was recommended to be the site used when measuring IVA for study purposes. ${ }^{31}$ Fourth, the echocardiographic studies were not performed simultaneously with right-heart catheterization. Fifth, pressures were measured invasively using fluid-filled catheters, which might be less sensitive to variations in diastolic pressures. Sixth, our study population included 3 patients with right-sided $\mathrm{HF}$ and 21 with $\mathrm{AF}$, which may have affected our results. Furthermore, 3 patients had asymmetrical septal hypertrophy among 8 patients with hypertrophic cardiomyopathy, and that could affect the values for mitral annular velocity. Finally, the normal ranges of IVV and IVA for humans are not yet established, so there is a need for a larger study using a control group of normal subjects to determine the normal ranges and cut-off values for these indices. Ruan and Nagueh reported normal values of septal IVV and IVA in 80 consecutive normal subjects to be $6.9 \pm 2.7 \mathrm{~cm} / \mathrm{s}$ and $2.52 \pm 0.11 \mathrm{~m} / \mathrm{s}^{2}$; respectively. ${ }^{32}$

\section{Acknowledgments}

This study was supported by a scholarship presented by Honjo International Scholarship Foundation, Tokyo, Japan.

\section{Disclosures}

There is no ethical problem or conflict of interest with regard to this manuscript.

\section{References}

1. Hunt SA, Abraham WT, Chin MH, Feldman AM, Francis GS, Ganiats TG, et al. 2009 Focused update incorporated into the ACC/AHA 2005 Guidelines for the Diagnosis and Management of Heart Failure in Adults: A Report of the American College of Cardiology Foundation/American Heart Association Task Force on Practice Guidelines
Developed in Collaboration With the International Society for Heart and Lung Transplantation. J Am Coll Cardiol 2009; 53: e1 -e90.

2. Kato N, Kinugawa K, Seki S, Shiga T, Hatano M, Yao A, et al. Quality of life as an independent predictor for cardiac events and death in patients with heart failure. Circ J 2011; 75: 1661-1669.

3. Asanuma H, Kitakaze M. The largest cohort study opens a new era for the management of heart failure in Japan. Circ J 2011; 75: 775776.

4. Nagueh SF. Echocardiographic assessment of left ventricular relaxation and cardiac filling pressures. Curr Heart Fail Rep 2009; 6: $154-159$.

5. Tschope C, Paulus WJ. Is echocardiographic evaluation of diastolic function useful in determining clinical care? Doppler echocardiography yields dubious estimates of left ventricular diastolic pressures. Circulation 2009; 120: 810-820.

6. Edvardsen T, Urheim S, Skulstad H, Steine K, Ihlen H, Smiseth OA. Quantification of left ventricular systolic function by tissue Doppler echocardiography: Added value of measuring pre- and postejection velocities in ischemic myocardium. Circulation 2002; 105: 2071 2077.

7. Li X, Jones M, Wang HF, Davies CH, Swanson JC, Hashimoto I, et al. Strain rate acceleration yields a better index for evaluating left ventricular contractile function as compared with tissue velocity acceleration during isovolumic contraction time: An in vivo study. $J$ Am Soc Echocardiogr 2003; 16: 1211-1216.

8. Hashimoto I, Li XK, Bhat AH, Jones M, Sahn DJ. Quantitative assessment of regional peak myocardial acceleration during isovolumic contraction and relaxation times by tissue Doppler imaging. Heart 2005; 91: 811-816.

9. Schattke S, Knebel F, Grohmann A, Dreger H, Kmezik F, Riemekasten $\mathrm{G}$, et al. Early right ventricular systolic dysfunction in patients with systemic sclerosis without pulmonary hypertension: A Doppler tissue and speckle tracking echocardiography study. Cardiovasc Ultrasound 2010; 8: 3 .

10. Tayyareci Y, Tayyareci G, Tastan CP, Bayazit P, Nisanci Y. Early diagnosis of right ventricular systolic dysfunction by tissue Dopplerderived isovolumic myocardial acceleration in patients with chronic obstructive pulmonary disease. Echocardiography 2009; 26: 10261035.

11. Tayyareci Y, Nisanci Y, Umman B, Oncul A, Yurdakul S, Altun I, et al. Early detection of right ventricular systolic dysfunction by using myocardial acceleration during isovolumic contraction in patients with mitral stenosis. Eur J Echocardiogr 2008; 9: 516-521.

12. Lindqvist $P$, Waldenstrom A, Wikstrom G, Kazzam E. The use of isovolumic contraction velocity to determine right ventricular state of contractility and filling pressures a pulsed Doppler tissue imaging study. Eur J Echocardiogr 2005; 6: 264-270.

13. Cho EJ, Caracciolo G, Khandheria BK, Steidley DE, Scott R, Abhayaratna WP, et al. Tissue Doppler image-derived measurements during isovolumic contraction predict exercise capacity in patients with reduced left ventricular ejection fraction. JACC Cardiovasc Imaging 2010; 3: 1 -9.

14. Ha JW, Oh JK, Ling LH, Nishimura RA, Seward JB, Tajik AJ. Annulus paradoxus: Transmitral flow velocity to mitral annular velocity ratio is inversely proportional to pulmonary capillary wedge pressure in patients with constrictive pericarditis. Circulation 2001; 104: $976-978$

15. Lang RM, Bierig M, Devereux RB, Flachskampf FA, Foster E, Pellikka PA, et al. Recommendations for chamber quantification: A report from the American Society of Echocardiography's Guidelines and Standards Committee and the Chamber Quantification Writing Group, developed in conjunction with the European Association of Echocardiography, a branch of the European Society of Cardiology. $J$ Am Soc Echocardiogr 2005; 18: 1440-1463.

16. Remme EW, Lysggen E, Halle-Valle T, Opdahl A, Pettersen E, Vartdal T, et al. Mechanics of preejection and postejection velocity spikes in left ventricular myocardium: Interaction between wall deformation and valve events. Circulation 2008; 118: 373-380.

17. Ashikaga H, van der Spoel TI, Coppola BA, Omens JH. Transmural myocardial mechanics during isovolumic contraction. JACC Cardiovasc Imaging 2009; 2: 202-211.

18. Sengupta PP, Khandheria BK, Korinek J, Wang J, Belohlavek M. Biphasic tissue Doppler waveforms during isovolumic phases are associated with asynchronous deformation of subendocardial and subepicardial layers. J Appl Physiol 2005; 99: 1104-1111.

19. Sengupta PP, Tajik AJ, Chandrasekaran K, Khandheria BK. Twist mechanics of the left ventricle: Principles and application. JACC Cardiovasc Imaging 2008; 1: 366-376.

20. Buckberg G, Hoffman JI, Nanda NC, Coghlan C, Saleh S, Athanasuleas C. Ventricular torsion and untwisting: Further insights into mechan- 
ics and timing interdependence: A viewpoint. Echocardiography 2011; 28: 782-804.

21. Buckberg G, Hoffman JI, Mahajan A, Saleh S, Coghlan C. Cardiac mechanics revisited: The relationship of cardiac architecture to ventricular function. Circulation 2008; 117: 2571-2587.

22. Notomi Y, Popovic ZB, Yamada H, Wallick DW, Martin MG, Oryszak SJ, et al. Ventricular untwisting: A temporal link between left ventricular relaxation and suction. Am J Physiol Heart Circ Physiol 2008; 294: H505-H513.

23. Luo X, Cao T, Li Z, Duan Y. A preliminary study on the evaluation of relationship between left ventricular torsion and cardiac cycle phase by two-dimensional ultrasound speckle tracking imaging. Int J Cardiovasc Imaging 2009; 25: 559-568.

24. Lyseggen E, Rabben SI, Skulstad H, Urheim S, Risoe C, Smiseth OA. Myocardial acceleration during isovolumic contraction: Relationship to contractility. Circulation 2005; 111: 1362-1369.

25. Bertini M, Sengupta PP, Nucifora G, Delgado V, Ng AC, Marsan NA, et al. Role of left ventricular twist mechanics in the assessment of cardiac dyssynchrony in heart failure. JACC Cardiovasc Imaging 2009; 2: 1425-1435

26. van Dalen BM, Kauer F, Vletter WB, Soliman OI, van der Zwaan $\mathrm{HB}$, Ten Cate FJ, et al. Influence of cardiac shape on left ventricular twist. J Appl Physiol 2010; 108: 146-151.
27. Nagueh SF, Middleton KJ, Kopelen HA, Zoghbi WA, Quinones MA. Doppler tissue imaging: A noninvasive technique for evaluation of left ventricular relaxation and estimation of filling pressures. $J \mathrm{Am}$ Coll Cardiol 1997; 30: 1527-1533.

28. Khouri SJ, Maly GT, Suh DD, Walsh TE. A practical approach to the echocardiographic evaluation of diastolic function. J Am Soc Echocardiogr 2004; 17: 290-297.

29. Knebel F, Eddicks S, Schimke I, Bierbaum M, Schattke S, Beling M, et al. Myocardial tissue Doppler echocardiography and n-terminal B-type natriuretic peptide (NT-proBNP) in diastolic and systolic heart failure. Cardiovasc Ultrasound 2008; 6: 45.

30. Nagueh SF, Appleton CP, Gillebert TC, Marino PN, Oh JK, Smiseth $\mathrm{OA}$, et al. Recommendations for the evaluation of left ventricular diastolic function by echocardiography. J Am Soc Echocardiogr 2009; 22: $107-133$.

31. Margulescu AD, Thomas DE, Ingram TE, Vintila VD, Egan MA, Vinereanu D, et al. Can isovolumic acceleration be used in clinical practice to estimate ventricular contractile function? Reproducibility and regional variation of a new noninvasive index. J Am Soc Echocardiogr 2010; 23: 423-431.

32. Ruan Q, Nagueh SF. Effect of age on left ventricular systolic function in humans: A study of systolic isovolumic acceleration rate. Exp Physiol 2005; 90: 527-534. 